\title{
Goldfish avoidance acquisition: Is the process classical, instrumental, or a phototaxis?
}

\author{
D. J. ZERBOLIO and L. L. WICKSTRA \\ University of Missouri, St. Louis, Missouri 63121
}

\begin{abstract}
Various active-avoidance procedures and controls were run using goldfish in a shuttlebox where the CS, when used, was a sudden onset of illumination. In terms of increasing "avoidance" performance over days of training, CS-only, response-contingent US-only, and timelapse groups showed significant "learning," whereas explicitly unpaired CS and US pseudoconditioning controls and US only (where US omission is not response contingent) did not show performance increases. The use of the pseudoconditioning procedure as a learning control for this animal seems questionable. Additionally, both classically and instrumentally trained groups showed high and comparable acquisition rates, confirming earlier findings. A negative phototaxis explanation is suggested that may account for these results.
\end{abstract}

Woodard and Bitterman (1973) concluded that shuttlebox avoidance acquisition in goldfish could be accounted for without reference to a process of instrumental learning (p. 128), which prompted Mackintosh (1974) to say that "goldfish would swim from one compartment of a shuttlebox to another just as readily when shocks were unavoidable as when a swimming response resulted in the omission of shock" (p. 304). One ordinarily expects acquisition rate to be augmented by instrumental over classical procedures, although there are a few exceptions (e.g., toe "twitch," Turner \& Solomon, 1962; nictitating membrane response, Gormezano, 1965). It is surprising, however, to find that the acquisition of a skeletal motor response of the complexity of swimming is not augmented by instrumental procedures. The work presented here is an attempt to replicate Woodard and Bitterman's basic finding with the addition of a few control groups suggested by Jensen (1961) and Kimble (1967).

\section{METHOD}

\section{Subjects}

The subjects were 110 goldfish, approximately $5-6 \mathrm{~cm}$ long, obtained from Ozark Fisheries. Upon receipt, subjects were housed in 30-gal aquaria until $48 \mathrm{~h}$ nrior to use, when they were transferred to 10-gal aquaria in $t$. experimental chamber. Twenty-four $h$ prior to use, subjects wete again transferred to $7.5 \times 11.5 \times 12.5 \mathrm{~cm}$ deep individual compartments, where they were housed for the duration of the experiment. The fish were fed daily, and temperature $\left(21.1^{\circ} \mathrm{C}\right)$ and $\mathrm{pH}(7 \pm .1)$ were held constant for the duration of the experiment. All housing was well aeriated and filtered at all times.

\section{Apparatus}

Subjects were run in four identical $29.2 \times 11.4 \times 11.4 \mathrm{~cm}$ deep shuttle tanks, comparable to those described by Horner, Longo, and Bitterman (1961), with a center hurdle with 45-deg sloping sides and a $9 \mathrm{~cm}$ long top, $6.35 \mathrm{~cm}$ high, over which water was maintained at a maximum of $2.5 \mathrm{~cm}$, comparable to the water clearance level used by Behrend and Bitterman (1962). Shuttling activity was monitored by photocells across the ends of the hurdle top. The conditioned stimulus (CS), evenly diffused by translucent plastic plates affixed to outside tank ends, was provided by blue $7-\mathrm{W} 110-\mathrm{V}$ ac Christmas tree lamps, comparable to those used by Wickstra and Zerbolio (1976), Woodard and Bitterman (1971), and Zerbolio (1976). The CS was the simultaneous onset of lamps at both ends of the shuttle tank. There was no illumination during the intertrial interval (ITI). The unconditioned stimulus (US) was delivered via $28 \times 10.2 \mathrm{~cm} \mathrm{22-gauge} \mathrm{stainless} \mathrm{steel} \mathrm{plates,} \mathrm{affixed} \mathrm{to} \mathrm{the}$ interior side walls at $7.5 \mathrm{~V}$ ac $(.66 \mathrm{~V} / \mathrm{cm})$, again comparable to the shock intensity employed by Woodard and Bitterman (1971, 1973). Only one US per trial was allowed. The US level $(.66 \mathrm{~V} / \mathrm{cm})$ at this duration $(200 \mathrm{msec})$ has been shown to provide maximum avoidance behavior in this apparatus (Zerbolio \& Wickstra, 1975). All events were programmed and recorded via appropriate circuitry.

\section{Procedure}

Eleven groups of 10 each were run 5 days at 20 trials/day, with a variable-interval (VI) 60-sec ITI. A trial consisted of a 10 -sec period during which, if a response (or responses) occurred, an "avoidance" was recorded. Only the initial response in the 10 -sec period produced the "avoidance" response, and additional responses were not counted. Thus, the maximum number of avoidances per day was 20 . The US, if it occurred, was at the end of the 10-sec period. The occurrence of a CS (blue light onset), the US (single 7.5-V ac 200-msec shock), or whether the subject's response terminated the CS and/or prevented the US are specified below for each of 11 separate groups.

Instrumental conditioning. Two instrumental (IC) groups were trained. Both were run such that US omission was contingent (USc) on the subject's response. If the subject responded in the 10-sec period prior to the US, the US was omitted on that trial. The two groups differed in the effect of their response on the CS. For the true IC group, the CS termination was contingent (CSc) on the subject's response, whereas, for a second modified IC group, CS termination did not occur (CSnc) with the subject's response (e.g., the CS remained on for a full $10 \mathrm{sec}$ irrespective of the subject's behavior). These procedures are comparable to those used by Woodard and Bitterman (1973).

Classical conditioning. Two classical (CC) groups were run such that US occurred on every trial, thus US presentation was not contingent on the subject's behavior. In the true CC group, CS termination was not contingent (CSnc) on the subject's response, whereas in the second modified CC group, a response in the CS interval terminated the CS for that trial (CSc). For these two groups (as well as for the two instrumental groups 
described above), CS and US presentations were paired, with each subject receiving potentially 20 CS-US pairings per day.

CS-only controls. The two CS-only groups received comparable training to the IC and CC groups, except that no US was ever presented. The first group had an instrumental CS (e.g., $\mathrm{CSc}$ ), and the second group had a classical CS (e.g., CSnc). If the subject responded during the 10-sec CS period, an "avoidance" equivalent response was recorded.

US-only controls. The IC and CC groups all had the potential of 20 US presentations each day. The US-only procedure was comparable, except that the CS was never presented. Rather, the 10 -sec period prior to the US was monitored for responses, exactly as if the CS had been presented. Two US-only groups were run, the first where a response in the 10 -sec period prior to the US would not produce US omission (USnc), and the second where a response in the 10 -sec period prior to the US yielded US omission (USc). The second procedure is, on the surface, similar to a Sidman avoidance schedule; however, trials here were presented at VI 60 -sec intervals rather than the fixed S-S interval characteristic of Sidman procedures.

Pseudoconditioning. Two pseudoconditioning (PC) groups were run. Forty stimuli (20 CSs, 20 USs) were presented to subjects in Gellerman series with a VI 30-sec ITI. The CS and US were never paired. Effectively, the 10-sec CS presentations, were, on the average, $60 \mathrm{sec}$ apart. Similarly, the average interval between US presentations was $60 \mathrm{sec}$. If a response occurred in the 10 -sec CS period, it was recorded as an avoidance equivalent, but responses to the CS had no effect on US presentations. All subjects received 20 USs each day of training. The first PC group was run such that CS termination was contingent (CSc) on the subject's response, while the second PC group had a classical CS (CSnc).

Time lapse. A single group of 10 subjects was run 20 trials a day for 5 consecutive days. Each trial consisted of a 10-sec period measured for incidence of "avoidance." These periods were spaced on a VI 60-sec base, comparable to the CS intervals of the other procedures, but neither a CS nor US was ever presented to these subjects.

\section{RESULTS AND DISCUSSION}

The mean number of avoidances for each of the 11 groups is shown in Figure 1. A two-way ANOVA with repeated measures revealed reliable differences between training procedures $[\mathrm{F}(10,99)=19.253$, $\mathrm{p}<.01]$, a reliable training effect $[\mathrm{F}(4,396)=101.886$, $\mathrm{p}<.01]$, and a reliable Training Procedure by Days interaction $[\mathrm{F}(40,396)=6.655, \mathrm{p}<.01]$. A partition of this interaction showed reliable increases in performance (learning?) for the true $\operatorname{IC}[\mathrm{F}(4,396)=36.392, \mathrm{p}<.01]$, modified IC $[\mathrm{F}(4,396)=40.196, \mathrm{p}<.01]$, true $\mathrm{CC}$ $[F(4,396)=31.127, \quad \mathrm{p}<.01]$, and modified $\mathrm{CC}$ $[F(4,396)=40.196, p<.01]$ groups. Thus, all of the learning groups showed substantial learning increases. Surprisingly, increases suggestive of learning were also shown by both the CS-only groups: CS only CSnc $[\mathrm{F}(4,396)=9.860, \mathrm{p}<.01]$ and $\mathrm{CS}$ only CSc $[F(4,396)=4.415, p<.01]$. Moreover, the time-lapse group $[\mathrm{F}(4,396)=5.325, \mathrm{p}<.01]$ and the US-only group with a response-contingent US (USc) $[\mathrm{F}(4,396)=$ $5.253, \mathrm{p}<.01]$ showed performance increases across days of training. Only the US-only USnc and the two pseudoconditioning groups (PC-CSc and PC-CSnc) did not show significant increases in avoidance over days of training $(\mathrm{F}=.811, .628$, and .872 , respectively).

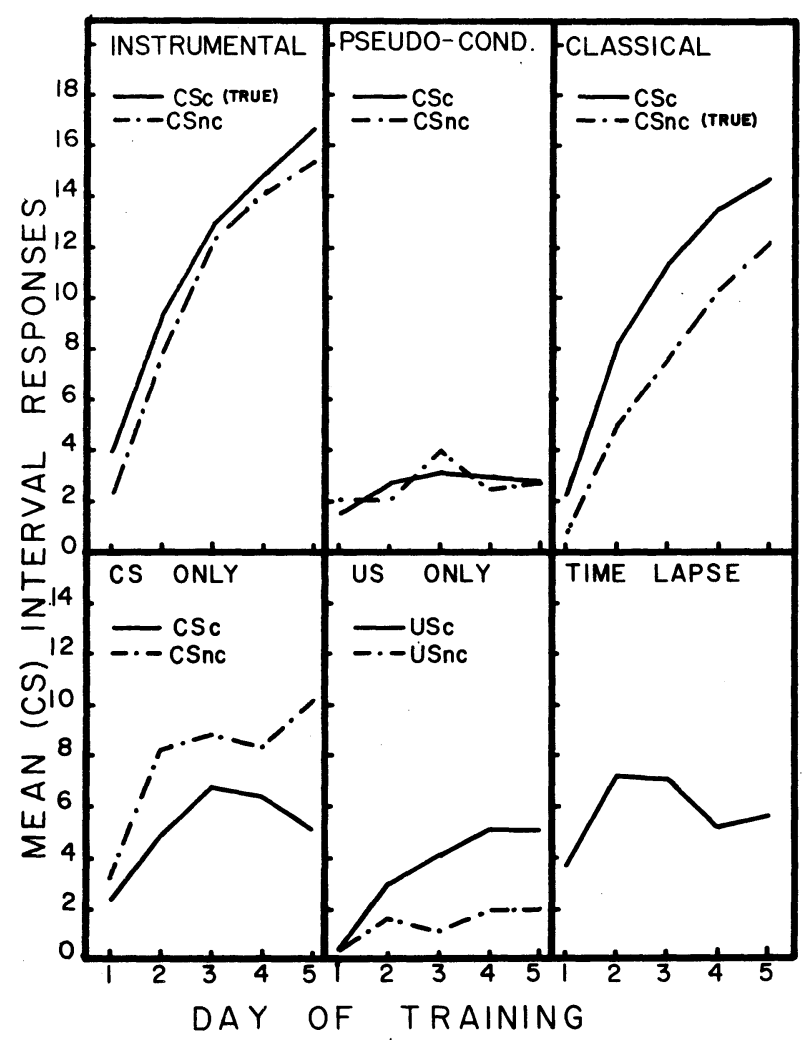

Figure 1. The mean number of trial intervals in which at least one response (avoidance or avoidance equivalent) occurs for all 11 groups. Shown are response-contingent CS termination (CSc) and noncontingent CS termination (CSnc), as well as responsecontingent US omission (USc) and noncontingent US procedures (USnc). True classical (CSnc, USnc) and true instrumental (CSc, USc) procedures are indicated.

Obviously, the traditional assumption that the pseudoconditioning control represents everything other procedures might do [i.e., CS only, US only, and time lapse (Kimble, 1967)] appears invalid for this animal. In fact, the very low levels of pseudoconditioning performance in the present study compared to the CSonly and time-lapse performances strongly suggest that, as Rescorla (1967) has pointed out, the pseudoconditioning paradigm, with explicitly unpaired CS and US may be a conditioned inhibition paradigm. Further work is presently in progress examining this question.

The present study also found that classical and instrumental procedures produce comparably high avoidance rates. These results certainly appear to confirm the results found by Woodard and Bitterman (1973) even though, in terms of response contingency, both classical and instrumental groups do better when the CS can be terminated via a shuttling response. However, there is a possible alternative to this conclusion. Zerbolio (1976) and Zerbolio and Wickstra (1975) concluded that, in a shuttlebox apparatus similar to that used in the present work, the superiority of groups with an illumination onset CS occurring on the end of the tank occupied by the fish at trial onset over groups 
with the CS onset on both sides or the side opposite can be explained by assuming that the pairing of CS and US augments a negative phototaxic, causing the animal to flee the same-end condition or to stay away from (avoid) the opposite-end stimulus. When the effect of the phototaxis is reduced by using an illuminated ITI and a color change CS, which provides identical positional information, the CS position-dependent effect fails to materialize (Zerbolio, 1976). If one adapts the phototaxis explanation to the present study, all of the learning groups have in common greater or lesser degrees of pairing of CS and US. Thus, the developed negative phototaxis may be the critical event controlling apparent avoidance performance. In other words the CS onset, and not the conditions of CS and/or US termination or omission, may be the primary parameter in this situation. All the learning groups, both classical and instrumental, have in common the conditions necessary to support the development of a strong negative phototaxis response to the CS onset, namely, a dark ITI, a sudden illumination onset CS, and CS-US pairing. With this interpretation, the superior performance of the responsecontingent CS termination groups in both the classical and instrumental procedures can be construed as an instrumentally acquired performance where the subject is terminating the negative phototactic stimulus. However, a test of the phototaxis alternative against the Woodard and Bitterman (1973) conclusion that goldfish learn this response classically, or whether or not response-contingent US omission plays a part in the acquisition of a conditioned avoidance response in this apparatus, will have to wait for further work.

\section{REFERENCES}

Behrend, E. R., \& Bitterman, M. E. Avoidance-conditioning in the goldfish: Exploratory studies of the CS-US interval. American Journal of Psychology, 1962, 75, 32-40.
Gormezano, I. Yoked comparisons of classical and instrumental conditioning of the eyelid response: And an addendum on "voluntary responders." In W. F. Prokasy (Ed.), Classical conditioning: $A$ symposium. New York: Appleton-CenturyCrofts, 1965.

Horner, J. L., Longo, N., \& Bitterman, M. E. A shuttle box for fish and a control circuit of general applicability. American Journal of Psychology, 1961, 74, 114-120.

JENSEN, D. D. Operationism and the question "Is this behavior learned or innate?" Behavior, 1961, 17, 1-8.

Kimble, G. A. Foundations of conditioning and learning. New York: Appleton-Century-Crofts, 1967.

Mackintosh, N. J. The psychology of animal learning. New York: Academic Press, 1974.

Rescorla, R. A. Pavlovian conditioning and its proper control procedures. Psychological Review, 1967, 74, 71-80.

TuRNER, L. H., \& Solomon, R. L. Human traumatic avoidance learning: Theory and experiments on the operantrespondent distinction and failure to learn. Psychological Monographs, 1962, 76(40, Whole No. 559).

Wickstra, L. L., \& Zerbolio, D. J., JR. Spatially located visual CS effects in conditioned avoidance shuttle response (CASR) acquisition in goldfish (Carassius auratus): Training over days. Bulletin of the Psychonomic Society, 1976, 8, 124-126.

Woodard, W. T., \& Bitterman, M. E. Classical conditioning of goldfish in the shuttle box. Behavior Research Methods \& Instrumentation, 1971, 3, 193-194.

Woodard, W. T., \& Bitrerman, M. E. Pavlovian analysis of avoidance conditioning in the goldfish (Carassius auratus). Journal of Comparative and Physiological Psychology, 1973, 82, 123-129.

ZERBolio, D. J., JR. Spatially located visual CS effects in conditioned shuttlebox avoidance in goldfish: A phototactic explanation. Bulletin of the Psychonomic Society, 1976, 8, 359-361.

ZERbolio, D. J., JR., \& WICKSTRA, L. L. The effect of power (US intensity by US duration) on shuttlebox avoidance acquisition in goldfish. Bulletin of the Psychonomic Society, 1975, 5, 345-347.

(Received for publication February 9, 1978.) 